Tohoku J. exp. Med., 1964, 84, 154-160

\title{
Further Study on $\beta$-Glucuronidase Activity of Bile in Cases with Calcium Bilirubinate Stones
}

By

\author{
Takeo Sato, Takashi Matsushiro, Takeshi Oikawa \\ and Hiroshi Sato \\ From the Department of Surgery, Tohoku University School of \\ Medicine, Sendai; Director: Prof. T. Maki
}

(Received for publication, June 29, 1964)

\begin{abstract}
The $\beta$-glucuronidase activity found in bile of patients with calcium bilirubinate stones is presumed to be significantly related to the pathogenesis of this type of gallstones. In this connection, this study presents evidence to show that $\beta$-glucuronidase in bile of those patients is predominantly of bacterial origin, mostly related to $E$. coli in bile, in contrast to the case of cholesterol stones in which the $\beta$-glucuronidase activity of bile is usually that of tissue $\beta$-glucuronidase. These results were obtained by comparative studies, on an individual basis, of the $\beta$-glucuronidase activities of bile, $E$. coli isolated from bile, serum and liver tissue.
\end{abstract}

Maki et al. ${ }^{1)}$ of the authors' department previously observed that the bile of the cases with calcium bilirubinate stones exhibited a strong activity iof $\beta$ glucuronidase. On the basis of such a fact, they presented a hypothesis that the enzyme hydrolyzes bilirubin glucuronide of bile to liberate free bilirubin and the latter combines with calcium to form a water-insoluble deposit of calcium bilirubinate as the first step in the formation of calcium bilirubinate stones. Moreover, since the optimum $\mathrm{pH}$ for the mentioned $\beta$-glucuronidase activity was found to be around 7.0 and comparable with that for bacterial $\beta$-glucuronidase, and since biliary infection is very common in the cases with calcium bilirubinate stones, it was presumed that the enzyme activity might be of bacterial origin. The present communication summarizes the results of subsequent experiments which seem to afford additional evidence to indicate that $\beta$-glucuronidase in bile of those patients is of bacterial origin, being apparently different from tissue $\beta$-glucuronidase.

\section{MATERIALS AND METHODS}

Bile specimens were obtained at laparotomy, by puncture of the gallbladder or the common bile duct, in five cases with calcium bilirubinate stones and in 10

佐藤丈夫, 松代 隆, 及川 健, 佐滕裕士 
cases with cholesterol stones as shown in Table I. In these samples, infecting bacteria were identified by culture, $\mathrm{pH}$ was measured with a $\mathrm{pH}$-meter of the ItoBeckmann type and the optimum $\mathrm{pH}$ for the $\beta$-glucuronidase activity was estimated by measuring the activity, by means of a modified Fishman method ${ }^{11}$, at various $\mathrm{pH}$ of the assay system.

TABLE I. Incidence of Biliary Infection with E. coli, Optimum $\mathrm{pH}$ for $\beta$-Glucuronidase Activity of Bile and $\mathrm{pH}$ of Bile in Gallstone Cases

\begin{tabular}{r|rl|l|c|c|c}
\hline Case & Age \& sex & $\begin{array}{c}\text { Kind of } \\
\text { gallstone }\end{array}$ & $\begin{array}{c}E . \text { coli } \\
\text { on culture }\end{array}$ & $\begin{array}{c}\text { Optimum pH } \\
\text { for } \beta \text {-gl. }\end{array}$ & $\mathrm{pH}$ \\
\hline 1 & 57 & M & & + & 7.3 & 6.8 \\
2 & 38 & M & Calcium & + & 5.8 & 7.8 \\
3 & 49 & F & bilirubinate & + & 6.7 & 6.8 \\
4 & 49 & F & stones & + & 6.8 & 6.7 \\
5 & 54 & F & & + & 6.8 & 6.9 \\
\hline 6 & 70 & F & & - & 4.6 & 6.7 \\
7 & 34 & M & & - & 5.1 & 6.7 \\
8 & 41 & F & & - & 5.1 & 7.6 \\
9 & 40 & F & Cholesterol & - & 4.6 & 7.2 \\
10 & 72 & F & stones & - & 6.2 & 7.5 \\
11 & 34 & F & & - & 3.8 & 7.7 \\
12 & 81 & F & & + & 4.6 & 7.6 \\
13 & 46 & M & & + & 4.4 & \\
14 & 56 & F & & - & 5.1 & \\
15 & 49 & M & & - & 4.6 & \\
& & & & & &
\end{tabular}

In some of the cases with calcium bilirubinate stones, Escherichia coli was isolated from bile by pure culture and processed into the suspension in isotonic sterile saline or into the filtrate of culture medium, and the samples were studied for the optimum $\mathrm{pH}$ of the $\beta$-glucuronidase activity. The serum and the liver homogenate specimens were also prepared in some cases of this series and subjected to the same study to determine the optimum $\mathrm{pH}$ for tissue $\beta$-glucuronidases.

\section{RESULTS}

$E$. coli was identified in bile in all the five cases with calcium bilirubinate stones and in three of the 10 cases with cholesterol stones (Table I). In Fig. 1 are shown the activity curves of $\beta$-glucuronidase of bile, plotted against $\mathrm{pH}$ of the assay system, in the calcium bilirubinate stone cases. The optimum $\mathrm{pH}$ for the activity ranged in these cases from 5.8 to 7.3. In the cholesterol stone cases, on the other hand, the optimum $\mathrm{pH}$ ranged between 3.8 and 6.2, as shown in Table $\mathrm{I}$, and was thus quite different from that in the case of calcium bilirubinate stones. As indicated also in Table I, $\mathrm{pH}$ of bile in the cases with calcium bilirubinate 


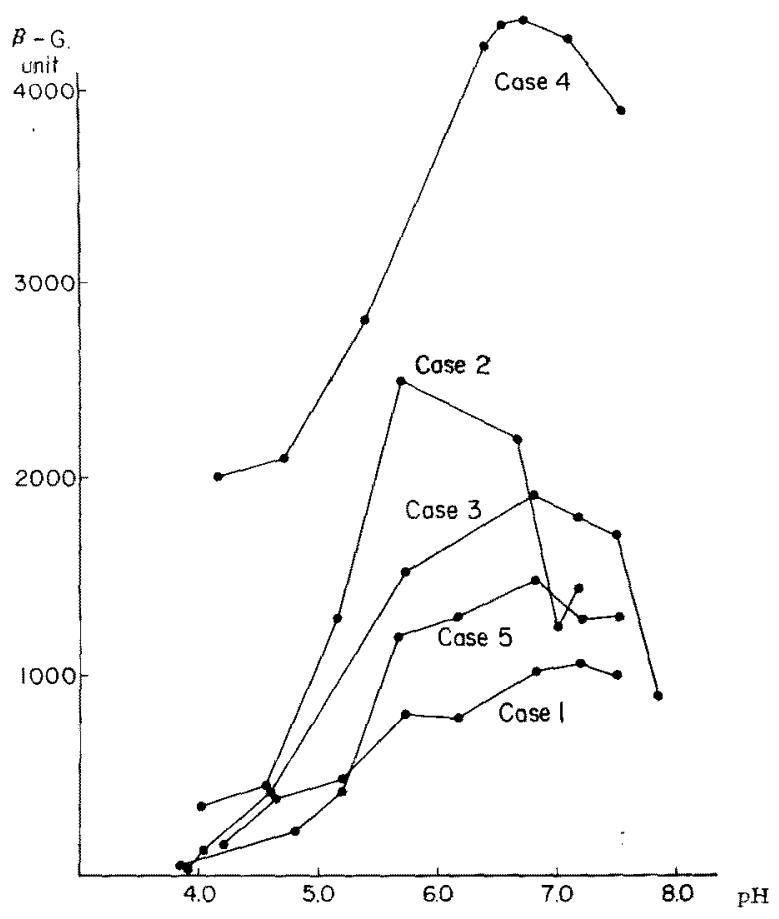

Fig. 1. The $\beta$-glucuronidase activities of bile in the cases with calcium bilirubinate stones at various $\mathrm{pH}$ of the assay system.

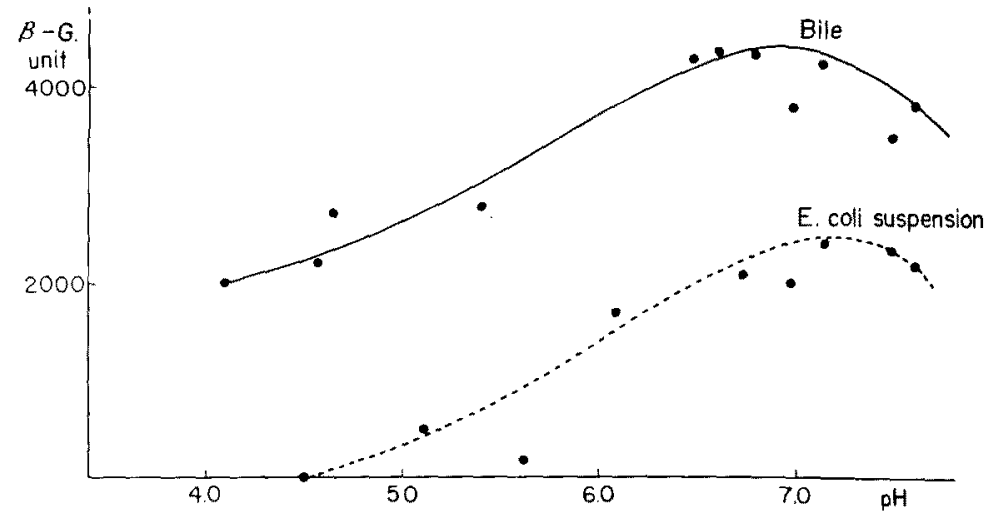

Fig. 2. The $\beta$-glucuronidase activities of bile and of a suspension of $E$. coli isolated from the same bile, in a patient (Case 4) with calcium bilirubinate stones. 


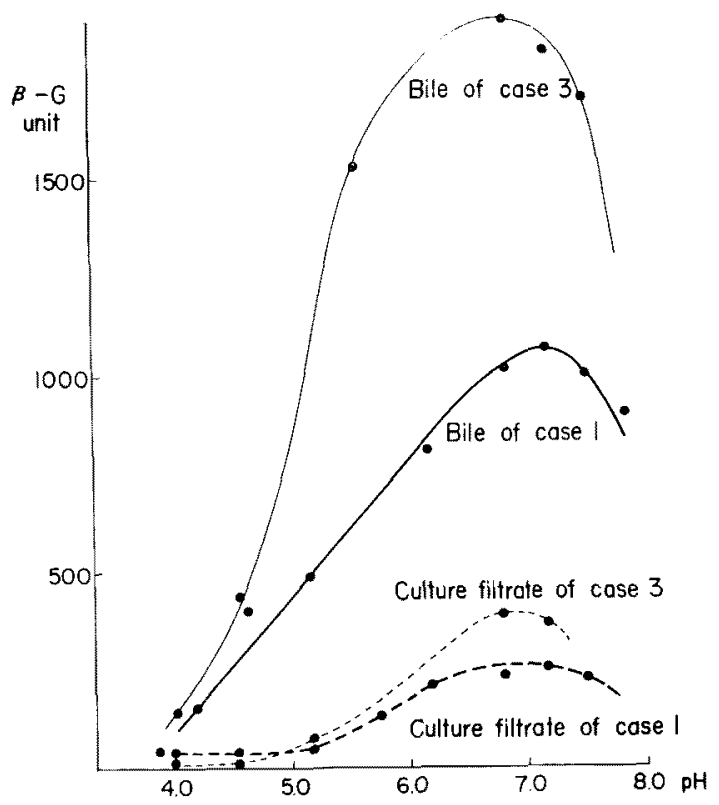

Fig. 3. The $\beta$-glucuronidase activities of bile and of a filtrate of culture of $E$. coli isolated from the same bile in patients (Cases $1 \& 3$ ) with calcium bilirubinate stones.

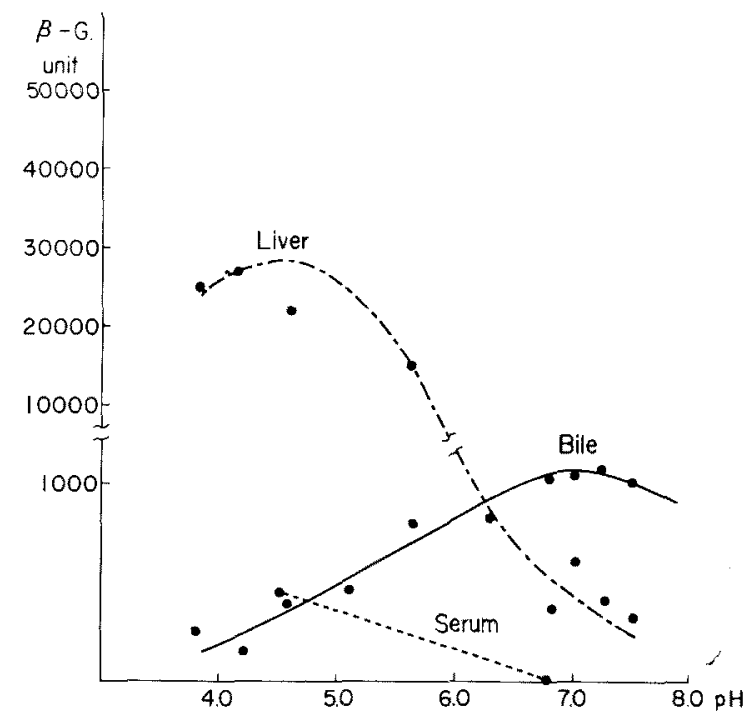

Fig. 4. The $\beta$-glucuronidase activities of bile, serum and liver homogenate of a patient (Case 1) with calcium bilirubinate stones. 


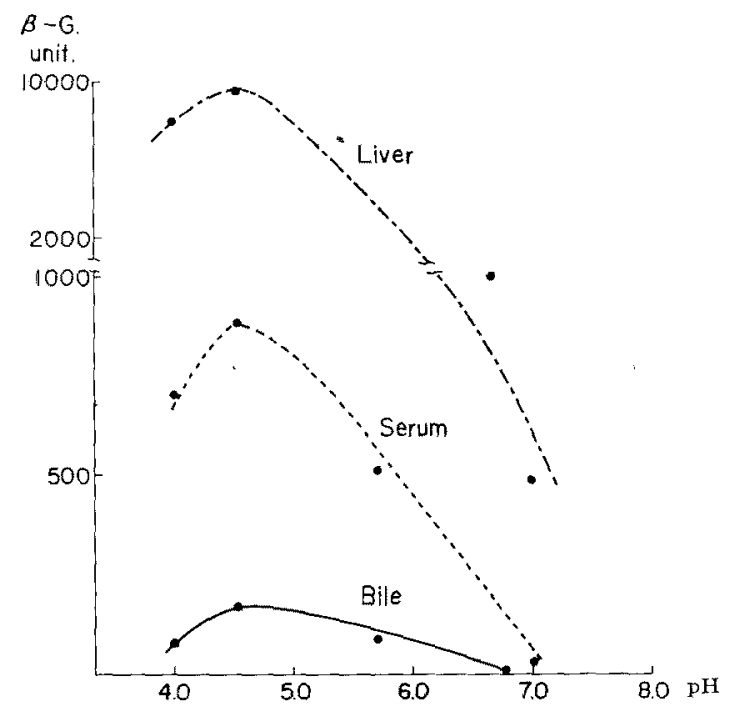

Fig. 5. The $\beta$-glucuronidase activities of bile, serum and liver homogenate of a patient (Case 6) with cholesterol stones.

stones ranged between 6.7 and 7.8 , and was close to the optimum $\mathrm{pH}$ for the $\beta$-glucuronidase activity of respective cases. On the other hand, $\mathrm{pH}$ of bile in the cholesterol stone cases ranged from 6.7 to 7.7 , with not much difference from those in the calcium bilirubinate stone cases, and was significantly different from the optimum $\mathrm{pH}$ of the $\beta$-glucuronidase activity of respective cases.

In the calcium bilirubinate stone cases, the optimum $\mathrm{pH}$ for the $\beta$ glucuronidase activity of the suspension of $E$. coli isolated from bile was found to approximately coincide with that of the bile specimen from which the bacteria were cultured. A typical example of the result is shown in Fig. 2. In this case, the optimum $\mathrm{pH}$ for the $E$. coli suspension was 7.1 as compared to 6.8 for the bile specimen. A similar result was obtained when the culture filtrate of $E$. coli was used instead of the bacterial suspension. In the cases shown in Fig. 3, for example, the optimum $\mathrm{pH}$ 's for the culture filtrates were 7.2 and 6.8 , while those for the corresponding bile specimens were 7.3 and 6.7 , respectively.

Fig. 4 compares the optimum $\mathrm{pH}$ for the $\beta$-glucuronidase activity among the bile, liver and serum specimens of a patient with calcium bilirubinate stones. The optimum $\mathrm{pH}$ for the bile specimen of this case was 7.3 , while those for the liver and serum specimens were both approximately 4.5, being quite different from the former. The result of a similar study in a case with cholesterol stones is shown in Fig. 5. In this case, the optimum $\mathrm{pH}$ for the $\beta$-glucuronidase activity was around 4.6 in the liver and serum specimens as well as in the bile specimen. 


\section{DISCUSSION}

Patterson ${ }^{2)}$ observed in 1937 that urinary estrogens were excreted in the form of conjugates but became free as urine putrefied. In 1949, Buehler et al. ${ }^{3)}$ succeeded in hydrolyzing estrogen conjugates and ketosteroid conjugates of urine with a culture filtrate of $E$. coli and ascribed the phenomenon to an enzymatic activity of the filtrate, i.e., the activity of bacterial $\beta$-glucuronidase. Subsequently, the characteristics as well as the refinement procedure of bacterial $\beta$-glucuronidase were studied by Doyle et al. ${ }^{4)}$ using a pure culture of $E$. coli isolated from patients of cystitis. Sasaki ${ }^{5}$ further elucidated that almost any kind of microorganisms, including bacilli of the coli family, subtillis bacilli, streptococci, eumyces, streptomyces and other fungi, were associated with the $\beta$-glucuronidase activity, although the activity of $E$. coli isolated from urine of cystitic patients was most intensive in his series.

According to Sasaki ${ }^{5}$, the $\beta$-glucuronidase activity of $E$. coli cultured from urine of cystitic patients showed a maximum at $\mathrm{pH}$ 7.0-7.5 when phenolphthalein glucuronide was used as the substrate. Using a number of different substrates, Wakabayashi and Fishman ${ }^{6}$ ) estimated the optimum $\mathrm{pH}$ for a $\beta$-glucuronidase preparation from $E$. coli (Sigma Chemical Co.) to be in the range between 4.5 and 8.0. Thus, although there is a variation according to the kind of substrate of the assay system, the optimum $\mathrm{pH}$ for $\beta$-glucuronidase of $E$. coli appears to be distributed around 7.0 and is quite different from that for tissue $\beta$-glucuronidase which is known to be 3.9-6.3.

It is well known, on the other hand, that the bile in the case of calcium bilirubinate stones is frequently infected with intestinal bacteria, mostly with $E$. coli. In fact, the cases of calcium bilirubinate stones examined in the authors' department were invariably associated with biliary infection with $E$. coli. It is therefore quite probable that the bile of patients with this type of gallstones is under a profound enzymatic influence of $E$. coli and may show a considerable activity of $\beta$-glucuronidase. To verify such an assumption, a previous experiment at the authors' department demonstrated that the bile of cases with calcium bilirubinate stones exhibited a strong activity of $\beta$-glucuronidase with its peak at $\mathrm{pH}$ near 7.0, whereas normal bile did not show such an activity ${ }^{1}$. A probable relation of such a bacterial $\beta$-glucuronidase activity of bile with the pathogenesis of clacium bilirubinate stones was already discussed ${ }^{1}$.

The results of the present study which was undertaken to further ascertain the bacterial origin of the $\beta$-glucuronidase activity of bile in the case of calcium bilirubinate stone cases are summarized as follows: (1) The optimum $\mathrm{pH}$ for the $\beta$-glucuronidase activity of bile is $5.8-7.3$ in the calcium bilirubinate stone cases, resembling the optimum $\mathrm{pH}$ for $\beta$-glucuronidase of $E$. coli, but is $3.8-6.2$ in the cholesterol stone cases. (2) In the calcium bilirubinate stone cases, the $\beta$-glucuro- 
nidase activity of the suspension or the culture filtrate of $E$. coli isolated from bile generally coincides in the optimum $\mathrm{pH}$ with that of the bile from which these bacterial preparations were obtained. (3) The optimum $\mathrm{pH}$ for the $\beta$-glucuronidase activity of serum or the liver homogenate and that for the $\beta$-glucuronidase activity of bile of the same patient are quite different in the calcium bilirubinate stone cases but well agree with each other in the cholesterol stone cases. These facts apparently indicate that $\beta$-glucuronidase in bile of the calcium bilirubinate stone cases is predominantly of bacterial origin, mostly originated from $E$. coli, while that in the case of cholesterol stones may be a tissue $\beta$-glucuronidase. However, the reason for the appearance of tissue $\beta$-glucuronidase, which is absent in normal bilo as reported previously ${ }^{1)}$, in bile of cases with cholesterol stones could not be elucidated in this study.

As revealed also in the present study, pH of bile is usually near 7.0, Accordingly, bacterial $\beta$-glucuronidase in bile of the calcium bilirubinate stone cases is presumed to be in an optimum condition as regards its activity. The activity of tissue $\beta$-glucuronidase in bile, on the other hand, may be far from a maximum at a normal $\mathrm{pH}$ of bile, since the latter is largely different from the optimum $\mathrm{pH}$.

\section{References}

1) Maki, T., Sato, To. \& Sato, Ta., Tohoku J. exp. Med., 1962, 77, 179.

2) Patterson, J., Brit. med. J., 1937, 2, 522.

3) Buehler, H.J., Katzman, P.A., Doisy, P.P. \& Doisy, E.A., Proc. Soc. exp. Biol., 1949, 72, 297.

4) Doyle, M.L., Katzman, P.A. \& Doisy, E.A., J. biol. Chem,, 1955, 217, 921.

5) Sasaki, A., Tohoku Igaku Zasshi (Jap.), 1959, 59, 797.

6) Wakabayashi, M. \& Fishman, W.H., J. Biol. Chem., 1961, 236, 996. 